\title{
CAMBIO DE PALABRAS CÉSAR HLDEBRANDT, PENGUIN RANDOM HOUSE GRUPO EDITORIAL: DEBATE, TERCERA REIMPRESIÓN: SETIEMBRE DEL 2018
}

\author{
CHANGE OF WORDSCÉSAR HILDEBRANDT, PENGUIN RANDOM \\ HOUSE PUBLISHING GROUP: DEBATE, THIRD PRINTING: \\ SEPTEMBER 2018 \\ (iD) Edgar Gutiérrez Gómez ${ }^{1 *}$ \\ egutierrez@unah.edu.pe \\ ${ }^{1}$ Universidad Nacional Autónoma de Huanta, Ayacucho, Perú \\ *Correspondencia: Edgar Gutiérrez Gómez. Email: egutierrez@unah.edu.pe
}

Recibido: 01.02.2020 | Aprobado: 13.03.2020

\section{RESUMEN}

Los acontecimientos políticos de una nación pautean el hito aglomerado de personajes referentes de opinión, que agitan a las masas por una determinada ideología política. Esa representación se sujeta en los políticos que representan a un partido político, a la vez tiene que sustentarse en ideologías programáticas con un órgano de difusión periodística que señala una regla en su proceso histórico, por ejemplo las luchas ideológicas en las industrias periodísticas: "El grupo tiende a asimilar todos los elementos capaces de reclamarse del socialismo sin exceptuar aquellos que provienen del radicalismo gonzálezpradista y se conservan fuera de los partidos políticos" (Mariátegui, 1986, p.99) Los aspectos registrados como epopeyas de la historia de los partidos políticos en el Perú, evidencian las luchas ideológicas ocurridas por mantener una posición en el entorno del trabajo periodístico. Como introducción permite profundizar el trabajo periodístico de César Hildebrandt que entrevistó a 25 políticos simbólicos de 1970 e inicios de 1980, esta compilación trae sus mejores entrevistas en su libro: Cambio de palabras, como revela Hildebrandt después de haber revisado su primera edición; confirmando en su segunda edición que hoy: "Los políticos ya no son primos de la cultura ni lectores con los que tratar una agenda que esté más allá de lo contingente. Se mueven en el ámbito avaro de una loseta y son parte de un ascenso social mal entendida" (p.23) Así encierra el prólogo de la segunda edición del libro, materia de la reseña actual.

Palabras clave: Comunicación social, periodismo.

\begin{abstract}
The political events of a nation guide the agglomerated milestone of opinion leaders, who agitate the masses for a certain political ideology. This representation is subject to the politicians who represent a political party, at the same time it has to be supported by programmatic ideologies with a journalistic diffusion organ that indicates a rule in its historical process, for example the ideological struggles in the journalistic industries: "The The group tends to assimilate all the elements capable of claiming socialism without excepting those that come from the gonzálezpradista radicalism and are preserved outside the political parties "(Mariátegui, 1986, p.99). Aspects recorded as epics in the history of political parties in Peru, they show the ideological struggles that occurred to maintain a position in the journalistic work environment. As an introduction it allows to deepen the journalistic work of César Hildebrandt who interviewed 25 symbolic politicians of the 1970s and early 1980s, this compilation brings his best interviews in his book: Change of words, as revealed by Hildebrandt after having reviewed its first edition; confirming in its second edition that today: "Politicians are no longer cousins of culture or readers with whom to deal with an agenda that is beyond what is contingent. They move in the miserly realm of a tile and are part of a poorly understood social ascent" (p.23) This is how the prologue of the second edition of the book, the subject of the current review, encloses.
\end{abstract}

Keywords: Social communication, journalism. 


\section{CAMBIO DE PALABRAS CÉSAR HILDEBRANDT, PENGUIN RANDOM HOUSE GRUPO EDITORIAL: DEBATE, TERCERA REIMPRESIÓN: SETIEMBRE DEL 2018}

Los políticos que llevan la estampilla de Hildebrandt como plausibles de pertenecer a un espacio académico están registrados en la Revista Caretas con diferencia de Javier Valle Riestra en Expreso y Mario Vargas Llosa en Diariouno que complementan el libro. El fundador del partido político vigente hasta la actualidad, independientemente de las simpatías de la masa popular y académica, es Víctor Raúl Haya de la Torre; aquello es lo primero que registra el libro de Hildebrandt, con fecha 3 de marzo de 1971, y comprende las páginas 15 al 60 de intenso debate académico y político, nada comparable con los políticos que expone la prensa actual. La entrevista contiene diferentes aspectos de la vida académica, también la opinión de distinguidos intelectuales del Perú y del mundo como: Ciro Alegría, Vargas Llosa y Manuel Gonzáles Prada; revela sobre César Vallejo que: "Antenor Orrego fue para él un maestro a todas horas. Yo he visto a Vallejo llorar a las tres de la mañana en París, en la Rotonda, al hablar de Antenor" (p.43) La entrevista conlleva una defensa férrea al APRA y las teorías políticas que sustentan su fundación y la llegada al poder del partido aprista.

Un paralelismo de la política actual, con los personajes entrevistados por Hildebrandt, distan en todo sentido como lo demuestra Vergara (2018, p.151) "Como es propio de la política peruana, generan partidos o movimientos ad hoc para cada elección, en los que el candidato está establecido aún antes de que el propio movimiento exista". El análisis articula con la entrevista de Hildebrandt a Jorge del Prado con fecha 17 de abril de 1972, uno de los políticos vinculados a la izquierda peruana, afirmando que: "Lo que queremos es que nuestro país se libere del imperialismo" (p.68) Complementan la entrevista abordando la esencia de las teorías ideológicas a nivel nacional e internacional sobre la política izquierdista. En una especie de abanicar el libro, se encuentra la entrevista al literato proveniente de familias de políticos del Perú, Alfredo Bryce Echenique fechado el 24 de julio de 1972. Abordan escenarios de la vida personal de Echenique, su estancia en París, la opinión sobre la influencia política de los literatos peruanos e internacionales que pautean la sociedad. Echenique con disímiles anécdotas por su descendencia de familia de políticos, y que no representaba nada en París, sobre una invitación de su estudiante, por ejemplo: "Entonces yo le dije: Soy Bryce Echenique, descendiente del presidente...Y me dijo: No, acá eres una porquería” (p.75)

Las entrevistas destacan un escenario especial a nivel internacional. Así en el año 1973, se entrevistó a Julio Cortázar el 6 de febrero y a Aníbal Quijano el 25 de febrero. Asevera Hildebrandt: "El mundo conoce a Valentina, la primera mujer cosmonauta, se inicia oficialmente la pugna Moscú-Pekín..., matan a John F. Kennedy, mueren Aldous Huxley..., Javier Heraud” (p.81) El año 2019, se cumplió los 50 años de algunas reformas velasquistas como el Decreto Supremo 006-69/EP, con consecuencias luctuosas para la población huantina-Ayacucho: "La investigación y composición de la letra de la canción "Flor de Retama" de Ricardo Dolorier fue tergiversado, por la población poco informada, como himno que caracteriza las protestas sociales inmiscuidas con sendero luminoso" (Gutiérrez, 2019, p.49) La entrevista de Hildebrandt a Velasco Alvarado en un contexto ajeno a su gobierno militar nacionalista: "No un país vendido, de rodillas. ¿Cómo era aquí? 
¡Aquí mandaba el embajador americano! Cuando yo era presidente, el embajador tenía que pedir audiencia y yo lo manejaba a seis pasos" (p.97) Se examinan las deportaciones a sus rivales políticos y la prensa que dio pedestal a su gobierno militar.

Por otro lado, la crónica universitaria no está alejada en las entrevistas de Hildebrandt y su componente esencial del academicismo que difiere actualmente, hoy monitoreado por la SUNEDU, que ordena las casas universitarias a nivel nacional. Está la entrevista a Luis Miró Quesada de la Guerra, director de El Comercio y docente universitario que enseñaba el curso de Filosofía de la Educación, siendo uno de sus estudiantes Haya de la Torre y, los artículos editoriales sobre el gobierno de Velasco, entrevista fechada el 17 de febrero de 1977. El mismo año, un 9 de junio, se realizó la entrevista a Héctor Cornejo Chávez quien planteó sus opiniones sobre la política peruana, indicando: "Creo que junto a ellos hay civiles, y también militares, que desearían marxistizar el proceso revolucionario del Perú (p.120) El 6 de abril de 1978, entrevistó a Pedro Beltrán Espantoso, registrándose las opiniones de Bustamante, Odría, La Prensa, Izquierda peruana, Morales Bermúdez y su lectura preferente sobre la economía, para Beltrán: "Marx es como Adam Smith" (p.137) La respuesta irónica presente en Borges: “...Discrepamos de muchas cosas, ¿verdad? Pero eso está bien. Porque entenderse es una miseria" (p.146) Entrevistando también, el 19 de diciembre de 1978, a Jorge Luis Borges que no cree que la muerte conduce Dios: "Desde luego, las Sagradas Escrituras, llamémosles así, aconsejan vivir hasta los 70 años. Yo he cumplido 79. Recuerdo cuando mi madre cumplió 98 años -ella murió a los 99- y me dijo: “¡Caramba, se me fue la mano!"” (p.140) Borges también se considera lector de la filosofía y, sus impulsos de plagiar; porque toda la cultura es plagio.

En este libro de Hildebrandt, materia de la reseña, se testimonia partes relacionadas al partido aprista. El 30 de julio de 1979 se entrevistó a Armando Villanueva, otro histórico aprista identificado con el pensamiento de Haya, quien indica: "Creo firmemente que en el Perú Haya es la expresión máxima del humanismo" (p.151) El culto a la personalidad se evidencia, luego plantea: "El capitalismo no se va a mantener en el Perú por voluntad de Armando Villanueva...Es un fenómeno mundial" (p.159) Bien avizorado para su época, sobre el crecimiento económico del capitalismo actual, se suma la entrevista de otro político aprista, Andrés Townsend Ezcurra, fechado el 17 de setiembre de 1979. Se manifiesta la defensa férrea de las líneas fundacionales del partido aprista, presente en Townsend, denunciando la extrema izquierda y derecha: "La derecha tiene, en efecto, un gran poder de infiltración. En eso se parece a la extrema izquierda. Pero creo que los apristas, que hemos nacido a la lucha para cambiar este país y que nos identificamos con las clases trabajadoras, estamos vacunados contra esa infiltración” (p.170)

Del mismo modo, se tiene el planteamiento del académico célebre que defiende la izquierda peruana, Julio Cotler, entrevistado el 24 de setiembre de 1979, quien propone sobre la izquierda peruana: "Y aquí la burguesía no tiene mucho que decir. Hernando de Soto tiene que traer a algunas vacas sagradas de Europa para promover una ideología de la burguesía" (p.178) Cree en la descentralización de políticos izquierdistas a nivel nacional y considera como ejemplo a Hugo Blanco que habla como ellos del pueblo. El 16 de octubre de 1979, se concretizó la entrevista a Enrique Chirinos Soto en temas relacionados a la política peruana de izquierda y derecha, que es la cadena esencial del 
libro de Hildebrandt, así sobre la inquisitoria pregunta de su situación de conservador, Chirinos manifestó: "Ja, ja ja...Yo soy conservador. Yo creo que en el Perú hay que conservar al Partido Aprista, la Fuerza Armada, la Iglesia católica y la democracia, una vez que la rescatemos" (p.194) Se considera un trabajador y no un oligarca. Cotler refirió a Hugo Blanco Galdós como político provinciano con una influencia positiva, Hildebrandt lo entrevistó el 5 de noviembre de 1979 y pudo entender que Blanco fue producto de una violencia y convive con ella: "Mi relación con la violencia es muy antigua. Porque desde niño fui testigo de la violencia ejercida por los poderosos y su aparato militar" (p.197) La democracia entendida para Blanco es el gobierno de la mayoría del pueblo. La relación con Hugo Blanco se encuentra presente en Alfonso Barrantes Lingán, entrevistado el 11 de febrero de 1980, donde se encuentran en una fórmula electoral: "Definitivamente Blanco va a ser nuestro candidato a la presidencia y con él vamos a dar la batalla electoral... (p.216) Y confiesa su pérdida de tiempo cuando militaba en el APRA.

La política merece una madurez y formación partidaria: "En cambio, en la juventud de ahora hay quienes quieren ser diputados iya! Es decir, hay impaciencia por el poder y por la sensualidad del poder" (p.229) En una entrevista realizada a otro aprista reconocido en la política peruana, Luis Alberto Sánchez, el 18 de febrero de 1980, se manifiesta del gobierno de Velasco que marcó un hito en la historia peruana sobre la diplomacia chilena: “...hay diferencias fundamentales entre las Fuerzas Armadas del Perú y Chile. El ejército peruano tiene una extracción de clase media, clase media baja y clases populares. Eso no sucede en Chile" (p.240) Es la opinión de Leónidas Rodríguez Figueroa, entrevistado el 3 de marzo de 1980. La filosofía existencial parte del efímero vivencial se encuentra en la entrevista a Juan Gonzalo Rose, el 10 de marzo de 1980, que alguna vez intentó matarse: "Sí, alguna vez... Tomé una cantidad de barbitúricos que consideré que iba a ser suficiente...” (p.247) Además, en su juventud, el azar de la vida era prioridad, ahora piensa en la muerte como una tentación de descanso.

Por otro lado, los gobernantes de un país siempre tienen algo en común, es así que Hildebrandt entrevistó a varios expresidentes peruanos. El 17 de marzo de 1980 entrevistó a Fernando Belaúnde Terry sobre su gobierno, en general sus debilidades y fortaleza, en especial sobre la página 11: "Fue una intriga política la que causó lo que se llamó después la cuestión de la página 11...” (p.255) Las controversias ideológicas del PPC y la intervención extranjera en su gobierno, pero lo que caracteriza es: "Esa superioridad que permite construir las obras de bien común, la escuela y el camino, aquello que he sintetizado en la frase: el pueblo lo hizo..." (p.264) De todo el material que contiene el libro, fuente de reseña actual es la entrevista con el novelista Manuel Scorza el 31 de marzo de 1980, cuyo contenido es controvertido a la posición de Hildebrandt sobre los literatos peruanos e internacionales. Sus contradicciones literarias serán una constante: "Yo he dado miles de reportajes en el mundo y he sostenido muchas veces posiciones contradictorias, según me cambie el humor, según la tarde, según la mujer con que estaba, según mi situación emotiva, según el otoño” (p.272) Es evidente el ego académico en esta entrevista controversial.

Por tanto, en esta aventura de entrevistas, Hildebrandt recorre personajes disímiles para la sociedad peruana, referentes indispensables para una generación posterior. Está la entrevista a Pablo Macera, el 5 de mayo de 1980, el académico referente en la historia 
peruana, quien manifestó que es innegable la presencia política del APRA y la izquierda peruana: "Creo que el APRA debería llegar al poder, a pesar de todos los peligros que pueda implicar para la izquierda. Aún más: creo que aceleraría el desarrollo de la izquierda. Todavía más: pienso que sería una experiencia psiquiátrica..." (p.284) Es para la opinión pública peruana los resultados actuales.

Por su parte, las relaciones políticas entre el Partido Popular Cristiano y el APRA se encuentran en Luis Bedoya Reyes, del 16 de junio de 1980, con el tucán de alto vuelo, como se autocalifica Bedoya. Sobre la visión de la pobreza peruana: “...evidentemente, no renuncio a mi propia vida ni a lo que yo puedo tener para mí o darles a los míos" (p.299) Su situación económica acomodada es producto de su trabajo. Uno de los nostálgicos de su infancia con ideales anárquicas es Javier Valle Riestra, quien el 10 de noviembre de 1982 califica a su partido: "En el aprismo hay, evidentemente, un fenómeno pequeñoburgués. Y los pequeñoburgueses somos algo anarquistas. Yo, por ejemplo, no creo en Césares ni en tribunos... Y creo que Haya era mucho más anarquista que marxista..." (p.302) El más crítico confeso contra Alán García. Termina el libro con uno de los literatos más importantes del Perú, Mario Vargas Llosa, el cual el 15 y 16 de noviembre del 1992, después de haber perdido las elecciones presidenciales con Alberto Fujimori, y sus constantes opiniones contrarias al gobierno fujimorista. Vargas Llosa es un defensor de la democracia moderna, enemigo de las dictaduras como la del 5 de abril, de Fujimori. Así, sobre la pena de muerte, manifiesta: "Soy un doctrinario enemigo de la pena de muerte. La pena de muerte no disuade y puede eternizar el error" (p.312) Se encuentra en esta entrevista el pensamiento de la economía liberal que coincide con Fujimori.

A manera de conclusión, es imprescindible hacer una relectura de la historia política peruana, resumida en Cambio de palabras de César Hildebrandt, para discernir sobre los políticos actuales que marcan la pauta de la demagogia sin militancia partidaria. Dentro de los 25 intelectuales entrevistados, siempre existen curiosidades o coincidencias sexistas, ya que no figura ninguna mujer política o académica que se haya tomado en cuenta en este libro de Hildebrandt; también se ventila a la juventud actual, la poca participación femenina en los debates políticos de las épocas de entrevista que hizo Hildebrandt. Es importante conocer la fuente originaria de los partidos políticos en el Perú para entender la precariedad de la política peruana con ribetes plagadas de corrupción.

\section{REFERENCIAS BIBLIOGRÁFICAS}

Gutiérrez, G. E. (2019). 50 años de la gesta huantina por la gratuidad de la educación. Puriq, 1(1), 41-50. doi:https://doi.org/10.37073/puriq.1.01.58

Mariátegui, J. C. (1986, p.99). Ideología y política. Chile: Biblioteca Amauta. Obtenido de https://www.archivochile.com/Ideas_Autores/mariategui_jc/s/Tomo13.pdf

Vergara, A. (2018, p.151). Ciudadanos sin república. De la precariedad institucional al descalabro político. Lima: Planeta Perú S. A. 